7-15-2015

\title{
Prevalence and Prediction of Obstructive Coronary Artery Disease in Patients Referred for Valvular Heart Surgery
}

\author{
Jason M. Lappe \\ Heart and Vascular Institute \\ Justin L. Grodin \\ Heart and Vascular Institute \\ Yuping Wu \\ Cleveland State University, y.wu88@csuohio.edu \\ Corinne Bott Silverman \\ Heart and Vascular Institute \\ Leslie Cho \\ Heart and Vascular Institute
}

Follow this and additional works at: https://engagedscholarship.csuohio.edu/scimath_facpub

Part of the Mathematics Commons

How does access to this work benefit you? Let us know!

\section{Repository Citation}

Lappe, Jason M.; Grodin, Justin L.; Wu, Yuping; Silverman, Corinne Bott; and Cho, Leslie, "Prevalence and Prediction of Obstructive Coronary Artery Disease in Patients Referred for Valvular Heart Surgery" (2015). Mathematics Faculty Publications. 218.

https://engagedscholarship.csuohio.edu/scimath_facpub/218

This Article is brought to you for free and open access by the Mathematics and Statistics Department at EngagedScholarship@CSU. It has been accepted for inclusion in Mathematics Faculty Publications by an authorized administrator of EngagedScholarship@CSU. For more information, please contact library.es@csuohio.edu. 


\title{
Prevalence and Prediction of Obstructive Coronary Artery Disease in Patients Referred for Valvular Heart Surgery
}

\author{
Jason M. Lappe, MD, MS, Justin L. Grodin, MD, Yuping Wu, PhD, Corinne Bott-Silverman, MD, \\ and Leslie Cho, MD
}

\begin{abstract}
Valvular heart disease is a common indication for cardiac surgery. Preoperative diagnostic coronary angiography (DCA) is routinely performed in patients who undergo valvular heart surgery (VHS). This practice is driven by the negative impact of untreated obstructive coronary artery disease $(\mathrm{CAD})$ on perioperative and long-term outcomes.' 3 The current American College of Cardiology Foundation and American Heart Association guidelines recommend that DCA be performed on all patients who undergo nonemergent VHS if there are symptoms of angina, left ventricular dysfunction, evidence of ischernia, or functional rnitral regurgitation. ${ }^{4}$ DCA is also recommended for patients with known histories of CAD or high pretest probability of CAD. In contrast, for patients with low or intermediate pretest probability of CAD, coronary computed tomographic angiography (CTA) is recommended. ${ }^{4}$ Yet there are no criteria defining low, intermediate, and high risk for CAD. Additionally, there are no tools to objectively assess a patient's risk for obstructive CAD before VHS. This study was focused on patients who underwent DCA before VHS, without known histories of CAD, and with low or intermediate pretest probability ofCAD. The aims were to determine the prevalence and risk factors associated with obstructive $\mathrm{CAD}$ in this population and to create a risk prediction nomogram to objectively assess preoperative risk for obstructive CAD. Ultimately, this information is intended to facilitate appropriate triage to either a coronary CTA or DCA before VHS.
\end{abstract}

\section{Methods}

Patients were identified from the Coronary Catheterization Database at the Cleveland Oinic. Patients were included if they underwent preoperative DCA for a primary indication of valvular heart disease from February 1, 2004, to October 1, 2013, underwent VHS within 6 months of DCA, and were $2: 18$ years of age. Patients were excluded if they had known $\mathrm{CAD}$, known ischernia by stress testing, or congenital heart disease. Patients were also excluded if they underwent DCA for a primary indication of angina. However, because angina can be a symptom of severe valvular disease, patients were included if they underwent DCA for a primary indication of valvular heart disease and had symptoms of angina, but not if they presented with ischernic symptoms and had valvular disease (a distinction defined in the Coronary Catheteriz.ation Database). 
Table 1

Baseline characteristics for the Entire cohort and divided According to the presence or absence of obstructive coronary artery disease

\begin{tabular}{|c|c|c|c|c|}
\hline \multirow[t]{3}{*}{ Characteristic } & \multirow{2}{*}{$\begin{array}{l}\text { Entire } \\
\text { Cohort }\end{array}$} & \multicolumn{2}{|c|}{ Obstructive CAD } & \multirow[t]{3}{*}{$\mathrm{p}$ Value } \\
\hline & & & & \\
\hline & $\left(\begin{array}{ll}n & 5360\end{array}\right)$ & $\begin{array}{ll} & \text { No } \\
\text { (n } & 4325)\end{array}$ & $\begin{array}{c}\text { Yes } \\
\text { (n } \quad 1035)\end{array}$ & \\
\hline Age (years) & $63 \pm 14$ & $60 \pm 13$ & $71 \pm 11$ & $<0.001$ \\
\hline Male & $57 \%$ & $55 \%$ & $63 \%$ & $<0.001$ \\
\hline $\begin{array}{l}\text { Body Mass Index } \\
\left(\mathrm{kg} / \mathrm{m}^{2}\right)\end{array}$ & 27 [24 30] & $27\left[\begin{array}{ll}24 & 30\end{array}\right]$ & $27\left[\begin{array}{ll}24 & 30\end{array}\right]$ & 0.20 \\
\hline Diabetes Mellitus & $16 \%$ & $13 \%$ & $28 \%$ & $<0.001$ \\
\hline Hypertension & $50 \%$ & $49 \%$ & $55 \%$ & 0.003 \\
\hline History of CVA or TIA & $8 \%$ & $8 \%$ & $10 \%$ & 0.04 \\
\hline History of smoking & $39 \%$ & $39 \%$ & $39 \%$ & 0.89 \\
\hline $\begin{array}{l}\text { Family history of } \\
\text { premature CAD }\end{array}$ & $8 \%$ & $7 \%$ & $9 \%$ & 0.12 \\
\hline Hyperlipidemia & $39 \%$ & $36 \%$ & $52 \%$ & $<0.001$ \\
\hline Renal dysfunction & $25 \%$ & $21 \%$ & $42 \%$ & $<0.001$ \\
\hline Aortic Valve surgery & $50 \%$ & $47 \%$ & $65 \%$ & $<0.001$ \\
\hline Mitral Valve surgery & $49 \%$ & $53 \%$ & $35 \%$ & $<0.001$ \\
\hline Tricuspid Valve surgery & $9 \%$ & $10 \%$ & $4 \%$ & $<0.001$ \\
\hline Multiple Valve surgery & $7 \%$ & $8 \%$ & $4 \%$ & $<0.001$ \\
\hline $\mathrm{ACE}$ or $\mathrm{ARB}$ & $44 \%$ & $43 \%$ & $49 \%$ & $<0.001$ \\
\hline Aspirin & $40 \%$ & $39 \%$ & $44 \%$ & 0.0 \\
\hline Beta blocker & $46 \%$ & $46 \%$ & $45 \%$ & 0.38 \\
\hline Statin & $35 \%$ & $32 \%$ & $46 \%$ & $<0.001$ \\
\hline
\end{tabular}

Comorbidities (diabetes, hypertension, hyperlipidemia, history of TIA or stroke) defined by ICD 9 Code. Renal dysfunction defined as a GFR $<60 \mathrm{mls} / \mathrm{min} / 1.73 \mathrm{~m}^{2}$ or the requirement of renal replacement therapy. Obstructive CAD defined as $\geq 50 \%$ stenosis in $\geq 1$ artery.

Continuous variables expressed as mean \pm standard deviation or median [interquartile range].

ACE angiotensin converting enzyme inhibitor; ARB angiotensin receptor blocker; CAD coronary artery disease, CVA cerebrovascular accident; TIA transient ischemic attack.

The presence of obstructive CAD was defined as $\geq 50 \%$ stenosis in $\geq 1$ artery as graded by the physician performing the procedure. A threshold of $\geq 50 \%$ stenosis was chosen as the definition of obstructive CAD on the basis of the American College of Cardiology Foundation and American Heart Association guidelines, in which a $>50 \%$ stenosis is a class IIa recommendation for bypass in patients who undergo noncoronary cardiac surgery. ${ }^{5}$ A threshold of $\geq 50 \%$ was specifically chosen over the class I recommended threshold of $\geq 70 \%$ stenosis on the basis of the goal of designing a preoperative screening tool. Using the threshold of $\geq 50 \%$ ensures that the risk prediction nomogram and the associated estimated risk for CAD provide a conservative estimate when being used to triage between CTA and DCA.

Clinical, imaging, and laboratory characteristics were obtained from the time of the DCA by querying the electronic medical record (Epic, Verona, Wisconsin). Co-morbidities such as diabetes, hypertension, hyperlipidemia, and stroke were identified by International Classification of Diseases, Ninth Revision, coding. Glomerular filtration rate was calculated using the Cockcroft-Gault equation, and renal dysfunction was defined as a glomerular filtration rate $<60 \mathrm{ml} / \mathrm{min} / 1.73 \mathrm{~m}^{2}$ or the requirement for renal replacement therapy. The Institutional Review Board at the Cleveland Clinic granted approval for this research.
Continuous variables are expressed as mean $\pm \mathrm{SD}$ or as median (interquartile range) for normal or non-normal distributions, respectively. Student's $t$ test or the Wilcoxon rank sum test was used to assess differences between groups for continuous variables. Categorical variables were compared using the chi-square test and are expressed as percentages. Logistic regression was used to estimate the odds ratios and $95 \%$ confidence intervals (CIs) for predictors of obstructive CAD. Covariates selected for multivariate analysis included age, gender, diabetes, hypertension, history of stroke or transient ischemic attack, smoking, family history of premature $\mathrm{CAD}$, hyperlipidemia, renal dysfunction, and the different valve surgical procedures (aortic valve, mitral valve, tricuspid valve, or multiple valve surgery).

A nomogram to predict the risk for obstructive CAD was constructed. Patients were randomly split in a $4: 1$ ratio into derivation and validation groups. The randomization was matched by age ( \pm 5 years) and by gender. Variables identified by multivariate regression as independent predictors of obstructive $\mathrm{CAD}$ were included in the nomogram. Within the derivation group, logistic regression was used to calculate the $\beta$ coefficients for each of the included variables. These $\beta$ coefficients were then applied to the validation group. The resultant model was validated by assessing Somers's D rank correlation between predicted probabilities and observed responses. Then, bootstrapping using 250 sample patients was used to penalize for possible overfitting. This information was also used to estimate C statistics and corresponding 95\% CIs. The performance of the final model was assessed in the validation cohort and corrected for overfitting. All analyses were performed using $\mathrm{R}$ version 3.0.2 (R Foundation for Statistical Computing, Vienna, Austria), and $\mathrm{p}$ values $<0.05$ were considered tol indicate statistical significance.

\section{Results}

We identified 5,360 patients without histories of CAD who underwent DCA as part of preoperative evaluation for VHS. Within the cohort, 1,035 patients $(19.3 \%)$ were found to have obstructive CAD (Table 1). Compared with patients without obstructive $\mathrm{CAD}$, those with obstructive $\mathrm{CAD}$ tended to be older, were more frequently male, and had a higher prevalence of co-morbidities, including diabetes, hypertension, hyperlipidemia, a history of transient ischemic attack or stroke, and renal dysfunction. Additionally, patients with obstructive CAD more often underwent aortic valve surgery compared with non aortic valve surgery.

Baseline characteristics stratified by specific valve surgery are listed in Table 2. Within the cohort of patients who underwent aortic valve surgery, the prevalence of obstructive CAD was higher in this group compared with those who underwent mitral, tricuspid, or multiple valve surgery. Additionally, patients who underwent aortic valve surgery were older than those who underwent mitral or tricuspid valve surgery and were more often male.

In univariate analyses, age had the strongest association with obstructive CAD (Table 3). The relation between age and obstructive CAD is depicted in Figure 1. As expected, the risk for obstructive CAD increased with age, but this relation was not linear. There was a steep increase in risk 
Table 2

Baseline characteristics According to valve surgery

\begin{tabular}{|c|c|c|c|c|c|}
\hline Characteristic & $\begin{array}{l}\text { Aortic Valve } \\
(\mathrm{n} \quad 2481)\end{array}$ & $\begin{array}{l}\text { Mitral Valve } \\
\left(\begin{array}{ll}n & 2285\end{array}\right)\end{array}$ & $\begin{array}{l}\text { Tricuspid Valve } \\
\quad(\text { n 200) }\end{array}$ & $\begin{array}{l}\text { Multiple Valve } \\
\quad(\mathrm{n} \quad 394)\end{array}$ & $\mathrm{p}$ Value \\
\hline Age (years) & $64 \pm 14$ & $60 \pm 12$ & $62 \pm 15$ & $65 \pm 14$ & $<0.001$ \\
\hline Male & $61 \%$ & $57 \%$ & $34 \%$ & $42 \%$ & $<0.001$ \\
\hline Body Mass Index $\left(\mathrm{kg} / \mathrm{m}^{2}\right)$ & $29 \pm 6$ & $27 \pm 6$ & $28 \pm 7$ & $28 \pm 7$ & $<0.001$ \\
\hline Diabetes Mellitus & $21 \%$ & $10 \%$ & $18 \%$ & $22 \%$ & $<0.001$ \\
\hline Hypertension & $56 \%$ & $44 \%$ & $45 \%$ & $58 \%$ & $<0.001$ \\
\hline History of CVA or TIA & $9 \%$ & $7 \%$ & $7 \%$ & $15 \%$ & $<0.001$ \\
\hline History of smoking & $40 \%$ & $38 \%$ & $40 \%$ & $43 \%$ & 0.07 \\
\hline Family history of premature CAD & $8 \%$ & $8 \%$ & $7 \%$ & $6 \%$ & 0.73 \\
\hline Hyperlipidemia & $46 \%$ & $33 \%$ & $30 \%$ & $37 \%$ & $<0.001$ \\
\hline Renal dysfunction & $25 \%$ & $21 \%$ & $37 \%$ & $40 \%$ & $<0.001$ \\
\hline Obstructive CAD & $26 \%$ & $14 \%$ & $11 \%$ & $10 \%$ & $<0.001$ \\
\hline ACEI or ARB & $45 \%$ & $41.8 \%$ & $42 \%$ & $50 \%$ & 0.01 \\
\hline Aspirin & $42 \%$ & $37 \%$ & $34 \%$ & $44 \%$ & $<0.001$ \\
\hline Beta blocker & $43 \%$ & $46 \%$ & $59 \%$ & $61 \%$ & $<0.001$ \\
\hline Statin & $42 \%$ & $29 \%$ & $25 \%$ & $34 \%$ & $<0.001$ \\
\hline
\end{tabular}

Comorbidities (diabetes, hypertension, hyperlipidemia, history of TIA or stroke) defined by ICD 9 Code. Renal dysfunction defined as a GFR $<60 \mathrm{mls} / \mathrm{min} /$ $1.73 \mathrm{~m}^{2}$ or the requirement of renal replacement therapy. Obstructive CAD defined as $\geq 50 \%$ stenosis in $\geq 1$ artery.

Continuous variables expressed as mean \pm standard deviation or median [interquartile range].

ACE angiotensin converting enzyme inhibitor; ARB angiotensin receptor blocker; CAD coronary artery disease; CVA cerebrovascular accident; TIA transient ischemic attack.

Table 3

Univariate predictors of obstructive coronary artery disease

\begin{tabular}{|c|c|c|}
\hline Predictors & Or $(95 \% \mathrm{CI})$ & $\mathrm{p}$ Valu \\
\hline Age (years) & $2.65(2.432 .89)$ & $<0.001$ \\
\hline Male & $1.38(1.21 .59)$ & $<0.001$ \\
\hline Body Mass Index (kg/m²) & $1.01(0.951 .08)$ & 0.72 \\
\hline Diabetes Mellitus & $2.49(2.122 .93)$ & $<0.001$ \\
\hline Hypertension & $1.23(1.081 .41)$ & 0.00 \\
\hline History of CVA or TIA & $1.28(1.021 .62)$ & 0.03 \\
\hline History of smoking & $1.01(0.881 .16)$ & 0.87 \\
\hline Family history of premature CAD & $1.22(0.961 .56)$ & 0.10 \\
\hline Hyperlipidemia & $1.92(1.682 .21)$ & $<0.00$ \\
\hline Renal dysfunction & $2.75(2.373 .2)$ & $<0.0$ \\
\hline Aortic Valve surgery & $2.13(1.852 .45)$ & $<0.00$ \\
\hline Mitral Valve surgery & $0.48(0.420 .56)$ & $<0.0$ \\
\hline Tricuspid Valve surgery & $0.42(0.30 .57)$ & $<0.0$ \\
\hline Multiple Valve surgery & $0.45(0.320 .63)$ & $<0.0$ \\
\hline $\mathrm{ACE}$ or $\mathrm{ARB}$ & $1.31(1.141 .5)$ & $<0.0$ \\
\hline Aspirin & $1.24(1.091 .43)$ & 0.00 \\
\hline Beta blocker & $0.94(0.821 .08)$ & 0.36 \\
\hline Statin & $1.82(1.582 .08)$ & $<0.0$ \\
\hline
\end{tabular}

Comorbidities (diabetes, hypertension, hyperlipidemia, history of TIA or stroke) defined by ICD 9 Code. Renal dysfunction defined as a GFR $<60 \mathrm{mls} / \mathrm{min} / 1.73 \mathrm{~m}^{2}$ or the requirement of renal replacement therapy. Obstructive CAD defined as $\geq 50 \%$ stenosis in $\geq 1$ artery.

ACE angiotensin converting enzyme inhibitor; ARB angiotensin receptor blocker; $\mathrm{CAD}$ coronary artery disease; $\mathrm{CVA}$ cerebrovascular accident; TIA transient ischemic attack.

starting at about 50 years of age. The risk for obstructive CAD in patients $\leq 50$ years of age was $4.2 \%$, while in patients $>50$ years of age, it was $23.0 \%$. The risk for obstructive CAD further increased with age, and in those $>65$ years of age, it reached $32 \%$. In contrast, for patients $\leq 40$ years of age, the overall risk for obstructive CAD was only $1.9 \%$.
In addition to the association between obstructive CAD and age, the univariate analyses identified associations between obstructive CAD and many traditional CAD risk factors. These risk factors included male gender, diabetes, hypertension, hyperlipidemia, and a history of transient ischemic attack or stroke (Table 3). Aortic valve surgery was associated with increased odds of obstructive CAD, whereas mitral valve, tricuspid valve, and multiple valve surgical procedures were associated with a decreased odds of obstructive CAD.

In multivariate analyses, age continued to have the strongest association with obstructive (Table 4). Interestingly, within the multivariate analyses, the specific dysfunctional valve was not associated with the prevalence of obstructive CAD. Variables of male gender, diabetes, hyperlipidemia, family history of premature CAD, and renal dysfunction remained associated with obstructive CAD. Hypertension was found to have a negative association with obstructive CAD. There was no interaction between the presence of hypertension and age, male gender, or therapy with aspirin, statin, $\beta$ blockers, angiotensin-converting enzyme inhibitors, or angiotensin receptor blockers.

To devise the CAD prediction nomogram, the 5,360patient cohort was randomly divided into a 4,286-patient derivation group and a 1,074-patient validation group. There were no differences in the baseline characteristics between these 2 groups (Supplementary Table 1). The nomogram incorporated age, gender, the presence of diabetes, hyperlipidemia, renal dysfunction, and a family history of premature CAD (Figure 2). Hypertension was not included in the nomogram given its negative association with obstructive CAD. However, before excluding this variable, the model was assessed with and without hypertension, and no statistically significant differences were noted. The specific valve being operated on was also not included in the nomogram, as this was not a significant variable in the 


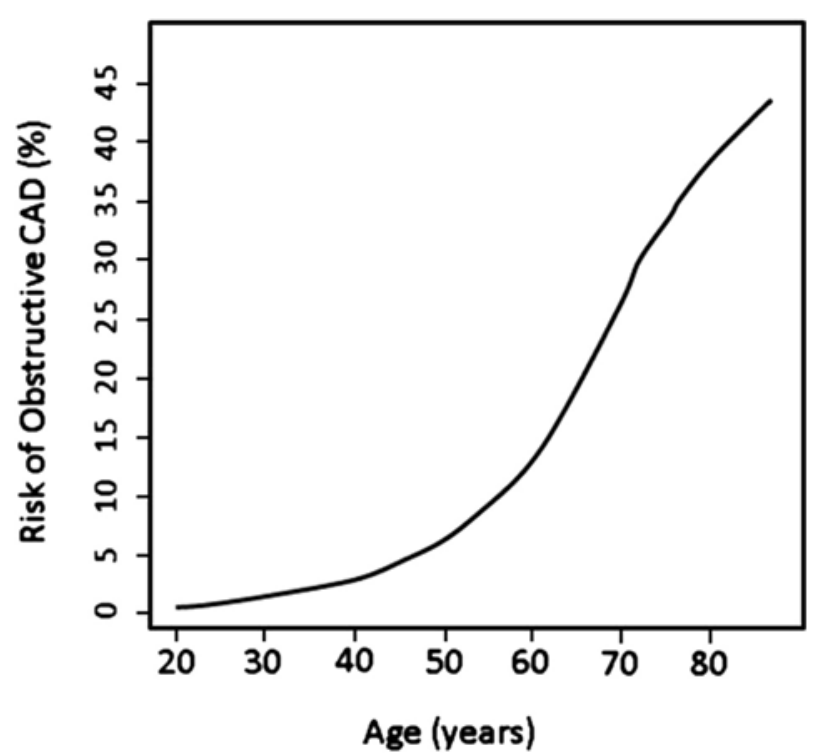

Figure 1. Risk for obstructive CAD by age.

Table 4

Multivariate analysis of predictors of significant coronary artery disease

\begin{tabular}{|c|c|c|}
\hline Predictors & Or $(95 \% \mathrm{CI})$ & $\mathrm{p}$ Value \\
\hline Age (years) & $2.41(2.172 .68)$ & $<0.001$ \\
\hline Male & $1.94(1.642 .3)$ & $<0.001$ \\
\hline Body Mass Index $\left(\mathrm{kg} / \mathrm{m}^{2}\right)$ & $0.99(0.91 .08)$ & 0.79 \\
\hline Diabetes Mellitus & $2.07\left(\begin{array}{ll}1.7 & 2.52\end{array}\right)$ & $<0.001$ \\
\hline Hypertension & $0.81(0.680 .97)$ & 0.02 \\
\hline History of CVA or TIA & $1.02(0.781 .34)$ & 0.87 \\
\hline History of smoking & $0.98(0.841 .16)$ & 0.85 \\
\hline Family history of premature CAD & $1.34(1.021 .76)$ & 0.04 \\
\hline Hyperlipidemia & $1.47(1.022 .1)$ & 0.04 \\
\hline Renal dysfunction & $1.47(1.211 .78)$ & $<0.001$ \\
\hline Aortic Valve surgery & $1.36(0.473 .96)$ & 0.57 \\
\hline Mitral Valve surgery & $0.95(0.322 .77)$ & 0.92 \\
\hline Tricuspid Valve surgery & $0.56(0.191 .63)$ & 0.29 \\
\hline Multiple Valve surgery & $0.46(0.131 .59)$ & 0.22 \\
\hline $\mathrm{ACE}$ or $\mathrm{ARB}$ & $1.16(0.981 .37)$ & 0.08 \\
\hline Aspirin & $0.95\left(\begin{array}{lll}0.81 & 1.12\end{array}\right)$ & 0.55 \\
\hline Beta blocker & $0.85(0.721)$ & 0.05 \\
\hline Statin & $0.91(0.641 .31)$ & 0.63 \\
\hline
\end{tabular}

Comorbidities (diabetes, hypertension, hyperlipidemia, history of TIA or stroke) defined by ICD 9 Code. Renal dysfunction defined as a GFR $<60 \mathrm{mls} / \mathrm{min} / 1.73 \mathrm{~m}^{2}$ or the requirement of renal replacement therapy. Obstructive CAD defined as $\geq 50 \%$ stenosis in $\geq 1$ artery.

ACE angiotensin converting enzyme inhibitor; ARB angiotensin receptor blocker; $\mathrm{CAD}$ coronary artery disease; CVA cerebrovascular accident; TIA transient ischemic attack.

multivariate analysis. Age was separated into 5-year increments and assigned points weighted to corresponding risk. Male gender and diabetes were assigned 3 points, renal dysfunction 2 points, and hyperlipidemia and a family history of premature CAD 1 point. The total score is depicted on the $\mathrm{x}$ axis and the corresponding risk for obstructive $\mathrm{CAD}$ on the y axis. A total score of 13 was associated with a $10 \%$ risk for obstructive CAD.

The final model was first validated for Somers's D rank correlation between predicted probabilities and observed

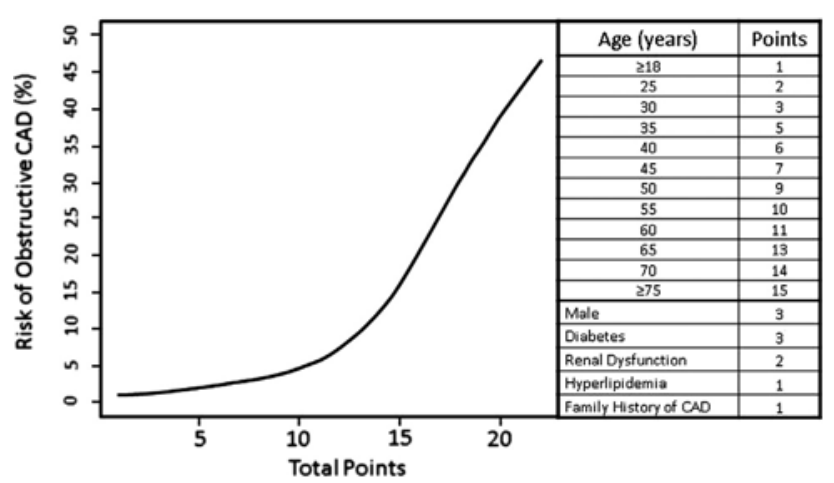

Figure 2. Risk prediction nomogram. The risk for obstructive CAD is estimated by first calculating a patient's risk score. The number of points assigned to the patient's age is noted at the right of the figure. Male gender and a history of diabetes are assigned 3 points, renal dysfunction is assigned 2 points, and hyperlipidemia and a family history of CAD are assigned 1 point. The summed total points on the $\mathrm{x}$ axis correspond to a predicted risk for obstructive $\mathrm{CAD}$ on the $\mathrm{y}$ axis. Five points correspond to a $2 \%$ risk for obstructive $\mathrm{CAD}, 10$ points to a $5 \%$ risk, 13 points to a $10 \%$ risk, and 15 points to a $17.5 \%$ risk. The bias corrected $\mathrm{C}$ statistic for the model is 0.765 (95\% CI 0.748 to 0.782 ).

responses. Next, 250 bootstrap samples were used to estimate $\mathrm{C}$ statistics and corresponding $95 \%$ CIs. The $\mathrm{C}$ statistic for the derivation cohort was 0.766 (95\% CI 0.750 to 0.783 ) and for the validation cohort 0.767 (95\% CI 0.751 to 0.784 ). The resulting optimism was 0.004 (95\% CI 0.001 to 0.006 ), which is sufficiently low to essentially exclude the possibility of overfitting. The bias-corrected $\mathrm{C}$ statistic was 0.765 (95\% CI 0.748 to 0.782 ).

\section{Discussion}

This study represents the largest evaluation of patients who underwent preoperative DCA preceding VHS to date. It was focused on those patients in whom the guidelines recommend either DCA or coronary CTA for preoperative coronary assessment. As expected, this study showed univariate associations between traditional cardiac risk factors and obstructive CAD. However, in multivariate analyses, there were no independent associations between the dysfunctional valve and obstructive CAD. Therefore, using only age, gender, and the presence or absence of risk factors, a model was successfully constructed to predict the risk for obstructive CAD. This model can be used to riskstratify patients who undergo preoperative evaluation before VHS and facilitate triage to the appropriate preoperative testing. Before this investigation, there were no available tools to objectively define risk in this population.

Within the study cohort, the observed prevalence of obstructive CAD was $19.3 \%$. This prevalence of obstructive CAD is lower than in cohorts with ischemic symptoms but concordant with other previous studies of asymptomatic patients. ${ }^{6}{ }^{8}$ In univariate and multivariate analyses, age had the strongest association with obstructive CAD. The weight of this association is reflected in the similarities between the curves seen in Figure 1, in which risk for obstructive CAD is plotted against age, and Figure 2, in which many traditional risk factors are included with age. 
Multiple studies have shown a correlation between obstructive CAD and aortic valve disease. ${ }^{11}$ This correlation is attributed to similar pathologic processes of coronary atheroma formation and valvular calcification. ${ }^{12}$ Conversely, studies have shown a decreased incidence between mitral valve disease and obstructive CAD. ${ }^{13}$ This study showed an increased incidence of obstructive CAD in patients who underwent aortic valve surgery and a decreased incidence in those who underwent mitral valve surgery. However, once these correlations were evaluated in context of the patient's age, they were no longer present. It is possible that the correlations seen between different valve lesions and obstructive CAD are the result of different valvular pathologies' predilections to present in certain age groups and the age-dependent nature of coronary atherosclerosis.

The nomogram in Figure 2 can be used to predict the risk for obstructive CAD in patients who undergo DCA as a part of a preoperative evaluation for VHS. Using readily accessible information about patient age, gender, and risk factors, a score can be calculated and cross-referenced with the curve to assess an estimated incidence of obstructive CAD. A score of 10 correlates with a $5 \%$ risk for obstructive CAD, while a score of 13 correlates with a $10 \%$ risk and a score of 15 with a $17.5 \%$ risk. Using this information, it would be reasonable to consider a patient with a score $\leq 13$ (i.e., a risk for obstructive CAD of $\leq 10 \%$ ) to be within the category of low or intermediate risk and therefore reasonable for coronary CTA instead of DCA.

The recommendation for preoperative coronary evaluation in low- or intermediate-risk patients using coronary CTA was first introduced in the 2014 version of the guidelines for valvular heart disease. ${ }^{4,14}$ By the time this occurred, the patients in this study had undergone their VHS. However, had they been prospectively evaluated using the nomogram from Figure 2, and delegated to CTA if their predicted risk for obstructive CAD was $<10 \%, 1,501$ patients $(28 \%)$ could have been triaged to preoperative coronary CTA. The majority of these patients would have undergone VHS without the additional risks, inconveniences, and costs of preoperative DCA. Fewer than 150 patients $(2.8 \%$ of the total) would have had positive results on coronary computed tomography and also required DCA. This is an acceptably low crossover rate, and given the high sensitivity of coronary CTA, this approach is very unlikely to result in a patient's going to VHS with undiagnosed obstructive CAD. ${ }^{15}$ Overall, this approach could result in significant reductions in patient risk and hospital costs. ${ }^{13}$

The conclusions of this study must be interpreted within the context of its limitations. This study was a retrospective analysis based on a cohort from a single tertiary referral center. We were unable to determine the type of valve dysfunction (stenotic vs regurgitant) or the underlying cause of the valve dysfunction (degenerative, infectious, and so on). In particular, we were unable to specifically exclude the patients with functional mitral regurgitation, although presumably those with ischemic mitral regurgitation would have been excluded on the basis of a history of CAD. Other potential limitations include the definition of co-morbidities on the basis of International Classification of Diseases, Ninth Revision, codes and a nonadjudicated definition of obstructive CAD.

\section{Disclosures}

Dr. Cho holds the Karos Chair for Women's Cardiovascular Research at the Cleveland Clinic.

\section{Supplementary data}

Supplementary data associated with this article can be found, in the online version, at http://dx.doi.org/10.1016/j. amjcard.2015.03.063.

1. Beach JM, Mihaljevic T, Svensson LG, Rajeswaran J, Marwick T, Griffin B, Johnston DR, Sabik JF, Blackstone EH. Coronary artery disease and outcomes of aortic valve replacement for severe aortic stenosis. J Am Coll Cardiol 2013;61:837-848.

2. Dahlberg PS, Orszulak TA, Mullany CJ, Daly RC, Enriquez Sarano M, Schaff HV. Late outcome of mitral valve surgery for patients with coronary artery disease. Ann Thorac Surg 2003;76:1539-1548.

3. Hollriegel R, Linke A, Hochadel M, Schuler G, Kerber S, Hambrecht R, Grube E, Hauptmann KE, Zahn R, Zeymer U, Senges J. Impact of coronary artery disease on in hospital mortality in patients with aortic valve disease. Results from the German ALKK registry. Herz 2013;38: 387-390.

4. Nishimura RA, Otto CM, Bonow RO, Carabello BA, Erwin JP 3rd, Guyton RA, O’Gara PT, Ruiz CE, Skubas NJ, Sorajja P, Sundt TM 3rd, Thomas JD. 2014 AHA/ACC guideline for the management of patients with valvular heart disease: executive summary: a report of the American College of Cardiology/American Heart Association Task Force on Practice Guidelines. J Am Coll Cardiol 2014:63:2438-2488.

5. Hillis LD, Smith PK, Anderson JL, Bittl JA, Bridges CR, Byrne JG Cigarroa JE, Disesa VJ, Hiratzka LF, Hutter AM Jr, Jessen ME, Keeley EC, Lahey SJ, Lange RA, London MJ, Mack MJ, Patel MR, Puskas JD, Sabik JF, Selnes O, Shahian DM, Trost JC, Winniford MD. 2011 ACCF/AHA guideline for coronary artery bypass Graft surgery. A report of the American College of Cardiology Foundation/American Heart Association Task Force on Practice Guidelines. Developed in collaboration with the American Association for Thoracic Surgery, Society of Cardiovascular Anesthesiologists, and Society of Thoracic Surgeons. J Am Coll Cardiol 2011;58:e123-e210.

6. Ramsdale DR, Bennett DH, Bray CL, Ward C, Beton DC, Faragher EB. Angina, coronary risk factors and coronary artery disease in pa tients with valvular disease. A prospective study. Eur Heart J 1984;5: $716-726$.

7. Kannel WB, McGee D, Gordon T. A general cardiovascular risk pro file: the Framingham Study. Am J Cardiol 1976;38:46-51.

8. Diamond GA, Forrester JS. Analysis of probability as an aid in the clinical diagnosis of coronary artery disease. N Engl J Med 1979;300: $1350-1358$.

9. Chobadi R, Wurzel M, Teplitsky I, Menkes H, Tamari I. Coronary artery disease in patients 35 years of age or older with valvular aortic stenosis. Am J Cardiol 1989;64:811-812.

10. Exadactylos N, Sugrue DD, Oakley CM. Prevalence of coronary artery disease in patients with isolated aortic valve stenosis. Br Heart J 1984:51:121-124.

11. Green SJ, Pizzarello RA, Padmanabhan VT, Ong LY, Hall MH, Tortolani AJ. Relation of angina pectoris to coronary artery disease in aortic valve stenosis. Am J Cardiol 1985;55:1063-1065.

12. Adler Y, Vaturi M, Herz I, Iakobishvili Z, Toaf J, Fink N, Battler A, Sagie A. Nonobstructive aortic valve calcification: a window to sig nificant coronary artery disease. Atherosclerosis 2002;161:193-197.

13. Lin SS, Lauer MS, Asher CR, Cosgrove DM, Blackstone E, Thomas JD, Garcia MJ. Prediction of coronary artery disease in patients undergoing operations for mitral valve degeneration. J Thorac Cardiovasc Surg 2001;121:894-901.

14. Bonow RO, Carabello BA, Chatterjee K, de Leon AC Jr, Faxon DP, Freed MD, Gaasch WH, Lytle BW, Nishimura RA, O'Gara PT, O'Rourke RA, Otto CM, Shah PM, Shanewise JS, Smith SC Jr, Jacobs AK, Adams CD, Anderson JL, Antman EM, Fuster V, Halperin JL, Hiratzka LF, Hunt SA, Nishimura R, Page RL, Riegel B. ACC/AHA 2006 guidelines for the management of patients with valvular heart disease: a report of the American College of Cardiology/American Heart Association Task Force on Practice Guidelines (Writing Com mittee to Revise the 1998 Guidelines for the Management of Patients 
With Valvular Heart Disease) developed in collaboration with the Society of Cardiovascular Anesthesiologists endorsed by the Society for Cardiovascular Angiography and Interventions and the Society of Thoracic Surgeons. J Am Coll Cardiol 2006;48:e1-e148.

15. Budoff MJ, Dowe D, Jollis JG, Gitter M, Sutherland J, Halamert E, Scherer M, Bellinger R, Martin A, Benton R, Delago A, Min JK. Diagnostic performance of 64 multidetector row coronary computed tomographic angiography for evaluation of coronary artery stenosis in individuals without known coronary artery disease: results from the prospective multicenter ACCURACY (Assessment by Coronary Computed Tomo graphic Angiography of Individuals Undergoing Invasive Coronary Angiography) trial. J Am Coll Cardiol 2008;52:1724-1732.

Post-print standardized by MSL Academic Endeavors, the imprint of the Michael Schwartz Library at Cleveland State University, 2017 